\title{
The Role of Ultrasound in Trauma
}

\author{
AJ Brooks, DMG Bowley
}

\section{Introduction}

The first papers were published on the regular use of ultrasound (US) in trauma in the early 1990s, nearly fifty years after the construction of the first ultrasound scanner. Since then US has become accepted and incorporated into algorithms for the investigation of abdominal trauma worldwide. Recent advances in technology have allowed the development of robust, hand-held scanners that have brought this equipment within the scope of the military. In this paper we review the literature on the use of US in trauma, discuss the focused technique developed for abdominal trauma scanning and consider the issues surrounding training and accrediting nonradiologists in US. The role of US in the military environment and its place in trauma algorithms are also discussed.

\section{History of the development of ultrasound in trauma}

The first case report on the use of US in the assessment of an injured patient was published by Kristensen in 1971 (1). This was followed by a series of reports describing the US detection of liver injuries and renal haematomas. In 1976, Asher (2) published a prospective study of 70 patients that demonstrated a sensitivity of $80 \%$ for US in the detection of splenic injury. Studies by Chambers (3) and Hoffman (4) suggested US as a non-invasive alternative to diagnostic peritoneal lavage (DPL), whilst Liu in a prospective comparison of US, DPL and computerised tomography (CT) concluded that the tests were complementary (5). In 1993, Rozycki published a prospective study that showed that surgeons could reliably diagnose haemoperitoneum following trauma using focused US (6). In 1995, Rozycki reported on Phase II of this study and introduced the acronym FAST 'Focused Abdominal Sonogram for Trauma' to describe the focused nature of the technique (7). This technique has become widely accepted and is now employed by most institutions that use US in the evaluation of injured patients.

\section{Trauma ultrasound versus other investigations}

McKenney (8) compared the value and reliability of US in blunt abdominal trauma in comparison to DPL and CT. They concluded that, if US had been the sole $\frac{\bar{C}}{\overline{\frac{D}{N}}}$. investigation, 199 of the 200 patients studied $\frac{\bar{\rho}}{\bar{\Phi}}$ would have had appropriate care. Bain (9)饮 found US to be superior to DPL as it led tow fewer non-therapeutic laparotomies in $a \overrightarrow{0}$ study that compared 220 US examinations $\overrightarrow{\vec{\omega}}$ by radiologists with 72 DPLs. In 1999,, Boulanger (10) compared an US-based investigation algorithm with a CT or DPLbased scheme to prospectively evaluate 706 ? patients; they found that the FAST algorithm for blunt abdominal injury was as accurate more rapid and less expensive than the alternatives.

The non invasive nature of US provides adistinct advantage both over DPL where theo morbidity from iatrogenic bleeding andô bowel injury is known to range between $0.5 \%$ and $5 \%(11)$ and in the initial assessment of paediatric injury where non operative management is frequently practised.

The sensitivity and specificity of ultrasound, DPL and CT are compared in Table 1 .

\section{FAST}

Rozycki's FAST technique emphasiseş four specific areas for attention: right upper quadrant; left upper quadrant; pelvis and

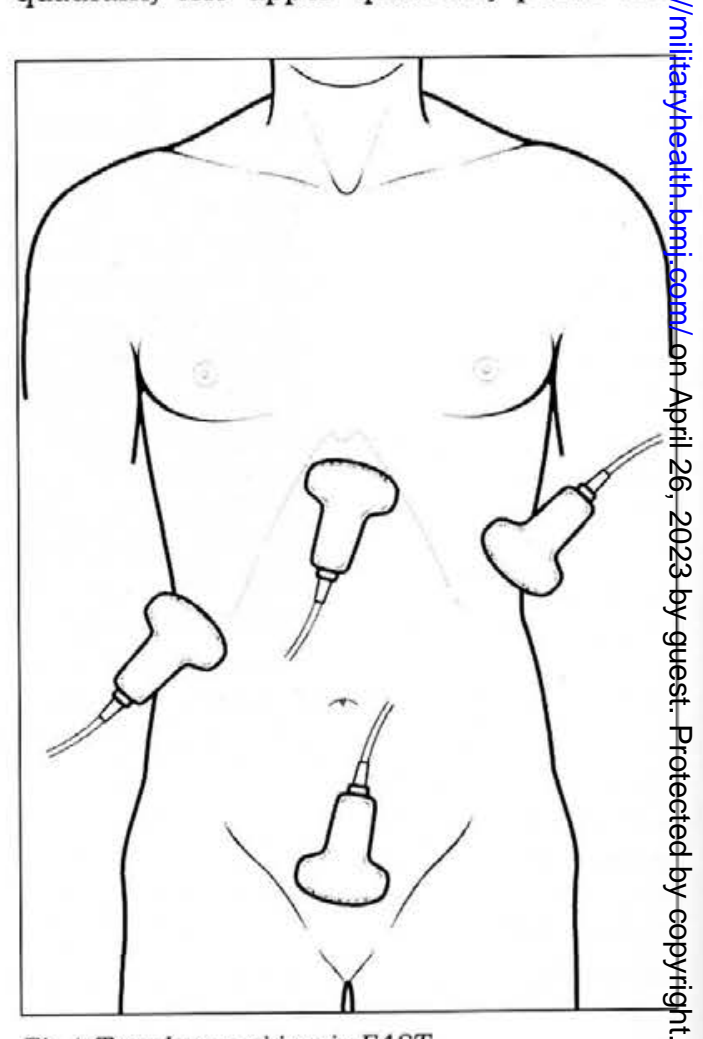

Fig 1. Transducer positions in FAST
MDHU Derriford, Plymouth
Capt A Brooks FRCS

Specialist Registrar in General Surgery

Centre, Nottingham

Maj DMG Bowley FRCS RAMC Specialist Registrar in 
Table 1. Comparison of DPL, CT and Ultrasound in the assessment of blunt abdominal trauma

\begin{tabular}{|l|c|c|}
\hline & Sensitivity \% & Specificity \% \\
\hline DPL[43] & 95 & 99 \\
\hline Computer Tomography[44] & 88 & 98 \\
\hline Ultrasound $[6,7,14-17]$ & $79-88.2$ & $90-99.7$ \\
\hline
\end{tabular}

pericardium (7). Various names have been used to describe the technique, however the International Consensus Conference on FAST in 1997 (12) proposed that 'Focused Assessment with Sonography for Trauma' best described the procedure for the initial evaluation of the trauma patient, and removed the implication that the technique was limited to the abdomen.

\section{FAST technique}

FAST is performed using real time US scanning of four distinct regions of the torso for the detection of fluid (blood). The regions are identified as the four P's: perihepatic, perisplenic; pericardial and pelvis (Figure 1). The procedure does not involve specific organ imaging and can be completed in 2 to 3 minutes. The investigation is performed early in the resuscitation; a $3.5 \mathrm{mHz}$ probe is applied using ultrasound gel to the four specific areas. The transducer is orientated sagitally in the subxiphoid region to identify the heart and look for blood in the pericardial sac. The probe is then placed in the right mid-axillary line between the eleventh and twelfth ribs to identify blood around the liver, kidney and diaphragm and in the hepato-renal pouch (Morrison's pouch). Blood is identified in the splenorenal and subdiaphragmatic spaces (Figure 2) with

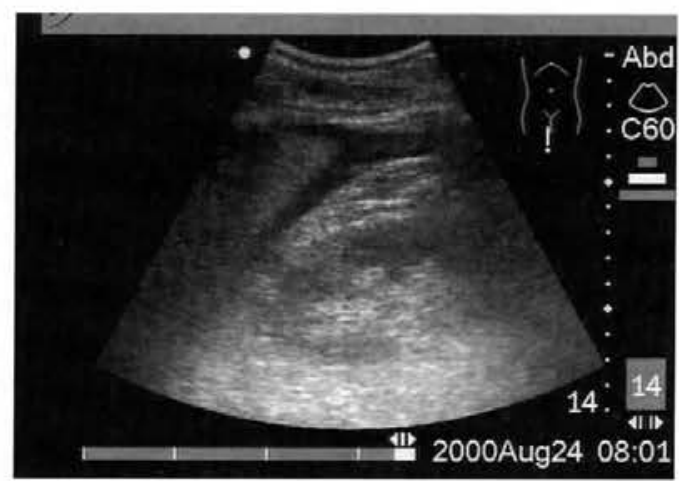

Fig2. Perisplenic scan showing haemoperitoneum.

Table 2. Review of the results of recent studies using FAST

\begin{tabular}{|l|c|c|c|c|}
\hline & Year & Patients & Sensitivity \% & Specificity \% \\
\hline Dolich[14] & 2001 & 2576 & 86 & 90 \\
\hline Healey[15] & 1996 & 745 & 88.2 & 97.7 \\
\hline McKenney[16] & 1996 & 1000 & 88 & 99 \\
\hline Rozycki[7] & 1995 & 371 & 81.5 & 99.7 \\
\hline Boulanger[17] & 1995 & 206 & 81 & 98 \\
\hline
\end{tabular}

the probe positioned in the left posterior axillary line between the tenth and eleventh? ribs. Fluid collecting in the pelvis is assessed with the probe turned for coronal sections? and angled inferiorly from $4 \mathrm{~cm}$ above the $\frac{\mathbb{}}{\varnothing}$ symphysis pubis.

Detection of blood in any of the fouro views is regarded as a positive examination, $\stackrel{\bullet}{\rightarrow}$ however, if any of the views are not clearly $\overrightarrow{\overline{\vec{s}}}$ seen then the examination is deemedo incomplete and an alternative means of investigation is required.

\section{The evidence for surgeon-}

performed ultrasound radiologist or surgeon-performed US in abdominal trauma attempted to detect organ injury in addition to haemoperitoneum. In 1992, Tso (13) used CT, DPL or laparotomy findings to confirm the US result. They demonstrated a sensitivity of only $69 \%$ in detecting intra-abdominal injury, but sensitivity of $91 \%$ for the detection of intra-abdominal fluid. This was shortly followed by Rozycki's paper (6) $\bigcirc$ where the emphasis was the detection of haemoperitoneum and values for sensitivity $\underline{\square}$ and specificity of $79 \%$ and $95.6 \%$ N respectively were reported. The detection of $\stackrel{\square}{\circ}$ haemoperitoneum has now become the accepted aim of trauma US. Numerous papers have now been published detailing

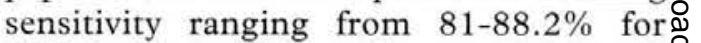
FAST with specificity of between $90-99.7 \% \frac{0}{\circ}$ $(7,14-17)$. See Table 2 . The largest series to $\vec{\Rightarrow}$ date was published in $2001 ; 2576$ patients $\frac{9}{3}$ were evaluated for blunt abdominal injury over thirty months in a Level 1 Trauma o Centre. US was found to have a sensitivity of $86 \%$, specificity of $98 \%$ and accuracy of $97 \%$ for the detection of intra-abdominal injuries (14).

Rozycki (18) compared a collected series $\stackrel{\varrho}{\vec{F}}$ of non-radiologist FAST examination with $\overline{0}$ radiologist performed trauma ultrasound. A $\stackrel{3}{-}$. combined total of 4941 patients from eleven $ᄋ$ studies underwent non-radiologist FAST with a sensitivity of $93.4 \%$, specificity of 9 $98.7 \%$ and an accuracy of $97.5 \%$ in $\frac{7}{0}$ detecting haemoperitoneum. This compared favourably to the series of 997 응 radiologist-performed FAST examinations N (sensitivity $90.8 \%$, specificity $99.2 \%$, స్心 accuracy of $97.8 \%$ ). The ability of surgeons to perform focused trauma ultrasound was 0 confirmed by Buzzas (19) who compared 518 patients evaluated with US by surgeons? to 324 patients at a second centre with $\frac{0}{0}$ radiologist-performed focused trauma US. $\overrightarrow{\mathbb{D}}$ There was no significant difference between $\frac{\mathbb{D}}{\mathbb{D}}$ the two groups in sensitivity, specificity or accuracy.

US is also easily repeatable; in one study, the use of serial examinations was shown to increase sensitivity from $83 \%$ to $89 \%$ 을 (9). 


\section{Disadvantages of trauma ultrasound}

There are a number of potential limitations with the use of US in trauma. The main concerns are image acquisition and problems with the interpretation of the images. US is limited by the technical factors that influence the acquisition of images such as obesity, extensive bowel gas or surgical emphysema. Satisfactory images, however, may not be diagnostic - as significant injuries may occur without haemoperitoneum or in the retroperitoneum (less well visualised) and free blood in the peritoneal cavity may not be identified by the examiner.

The issue of a negative FAST examination was reviewed at the International Consensus Meeting held at the R. Adams Cowley Shock Trauma Center, MD, USA(12). The meeting concluded that a negative FAST exam should be followed up with a period of observation of at least 6 hours and a repeat FAST. This approach is included as a component of many trauma algorithms (20). Further doubt was cast on the reliability of a negative FAST in papers by Chiu (21) and Ballard (22). Chiu (21) reported a series of 15 patients with abdominal injury without haemoperitoneum amongst a group of 772 patients evaluated, initially using FAST, and subsequently confirmed by an alternate investigation. The FAST examination in all 15 patients was interpreted as negative but subsequent $\mathrm{CT}$, whilst confirming the absence of haemoperitoneum, detected occult solid organ injury. Four patients failed non-operative management in this series and proceeded to laparotomy for splenic injury.

Ballard (22) assessed the incidence of false negative FAST in patients at risk of occult injury. A high incidence of false negative FAST was demonstrated in patients with pelvic fracture and the conclusion reached that these patients should have a negative FAST augmented by CT.

\section{Scoring Systems}

Attempts have been made to use scoring systems to quantify the amount of free intraperitoneal blood and aid the decision whether to operate. In 1994, Huang (23) developed such a system using scores from 0 to 8 . Scores of 3 or more required laparotomy. Unfortunately, the number of patients was limited in the study and the system did not predict the need for laparotomy well. McKenney's (24) system had a better negative predictive value. However, neither system has been shown to be ideal and further work is required if scoring systems to accurately quantify fluid and predict laparotomy are to be successfully incorporated into FAST protocols.

\section{Ultrasound in penetrating} abdominal trauma

Most reports on the use of US in trauma concentrate on its role in blunt abdominal? trauma as to date the results of US aftero penetrating injury have been disappointing. $\bigcirc$ Kahdi (25) used US to evaluate 75 patientso with penetrating abdominal injury without obvious need for laparotomy. Twenty-two patients had a falsely negative US giving an? overall sensitivity of $46 \%$ and a specificity of $\overline{\text {. }}$.

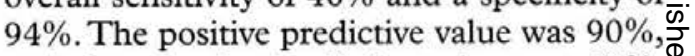
and the negative predictive value was $60 \%$. The authors concluded that a positive USi after penetrating injury was a strong $\vec{\circ}$ predictor of significant injury, but if negative, $\vec{\overrightarrow{ }}$ additional diagnostic studies should be $\omega_{\infty}^{\omega}$ performed to rule out occult injury.

US has also been used to evaluate penetrating wound tracts in the? thoracoabdominal region. Fry (26) used a high frequency $7.0 \mathrm{MHz}$ transducer toळे provide sufficient resolution for the assessment of pleural or peritoneal breacho and showed a positive and negative accuracy of $100 \%$.

\section{Other applications of US in trauma}

The evaluation of fluid in the pericardium 8 has become a standard part of the FAST assessment after blunt trauma (27). In 1996, Rozycki (28) showed that surgeon- 응 performed ultrasound in her institution was rapid and accurate for diagnosing $\mathbb{Q}$ haemopericardium. This was followed by $a_{\overrightarrow{0}}$ prospective, multi-centre study of the US3 evaluation of 261 patients with a penetrating precordial or transthoracic wound suspicious: for cardiac injury (29). There were 293 $(11.1 \%)$ true positive examinations and no false positives with an accuracy of $97.3 \% . \frac{2}{2}$ They concluded that ultrasound should be the investigation of choice for the initial evaluation of penetrating precordial wounds. $\frac{3}{3}$

US has also been shown to be valuable in:the detection of haemothorax. Sisley (30) compared the time and accuracy of thoracic ultrasound with the supine chest X-ray for ${ }^{3}$ the detection of traumatic effusion. Theo sensitivity $(97.4 \%)$ and specificity $(99.7 \%) \stackrel{\text {. }}{\text {. }}$ were similar to those for the portable chesto X-rays $(92.5 \%$ and $99.7 \%$ respectively), N however, the performance time for US was significantly shorter.

In 2001, Dulchavsky (31) reported on the evaluation of US in the detection of pneumothorax in 381 patients where there was high suspicion of injury. By assessing the presence or absence of pleural-lung sliding $\underset{\Omega}{\mathbb{\$}}$ they detected 37 of 39 pneumothoraces that were confirmed on chest X-ray $(95 \%$ sensitivity).

Thoracic US is unlikely to replace chest $\mathrm{X}-\frac{0}{2}$ ray, but it may expedite treatment in many. patients and may prove advantageous for the? detection of haemothorax or pneumothorax 


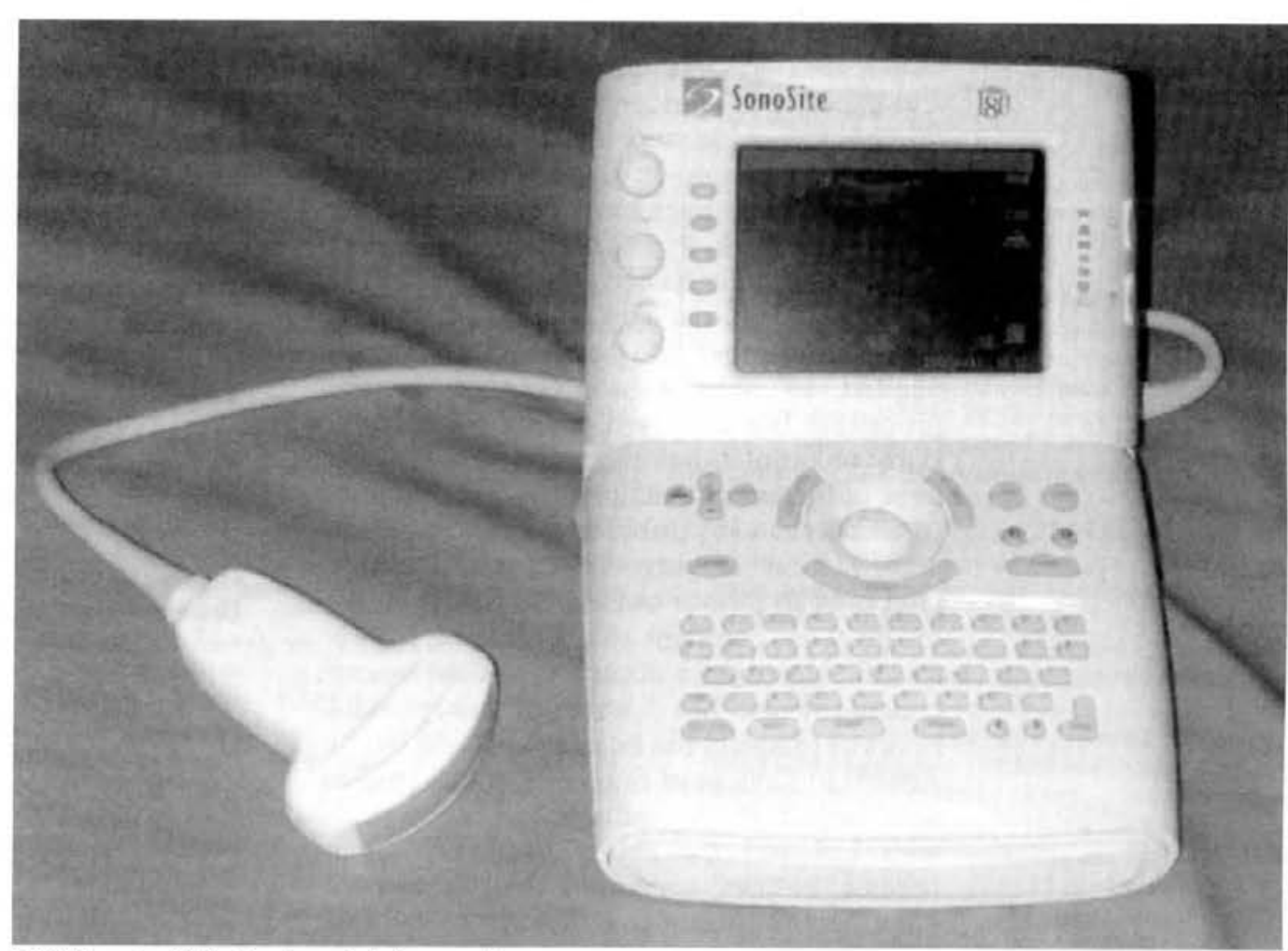

in an austere environment.

US has also been shown to be potentially useful in the diagnosis of sternal fracture in a series of 16 patients (32).

\section{Ultrasound in trauma algorithms}

US can be employed either as the definitive diagnostic study or as an adjunct to other modalities in blunt abdominal trauma; however, its limitations and the significance of a negative examination must be recognised. Most institutions employ an algorithm for the investigation of blunt abdominal trauma where the haemodynamic status of the injured patient is paramount. Rozycki (18) has suggested an algorithm for the investigation of blunt abdominal trauma that uses US as the primary investigation. Available evidence suggests that US is an ideal screening investigation for haemoperitoneum in the initial phase of the resuscitation of the severely injured patient. A positive examination mandates laparotomy in an unstable patient and requires further evaluation by CT in the stable patient without indications for immediate exploratory surgery. In the unstable patient with equivocal clinical findings on abdominal examination the role of US is equivalent to DPL. As discussed above, a negative examination should not be relied upon and should either be repeated $(12,20)$ or an alternative investigation be employed.

\section{Mass Casualty and Military Use}

US was first used in the mass casualty environment as a triage tool by Sarkisian to assess more than 400 victims of the 1988
Armenian earthquake (33). Intraperitoneal pathology was detected in $12.75 \%$ of patients.

During armed conflict, abdominal wounds are common, life-threatening and are the wounds for which surgery has the greatest impact on overall survival (34). However, in a series of 1350 laparotomies from the Vietnam War, based on clinical assessment of wounded soldiers, the rate of negative laparotomy was $19.2 \%$ (35). Therefore, in a military setting, an accurate screening tool for abdominal injury would be highly valuable as resources will, inevitably, be scarce.

In 1999 in Croatia, Sustic demonstrated that US is valuable under war conditions for the assessment of haemoperitoneum in abdominal injuries (36).

Technological advances have led to the development of portable, hand-held US 을 scanners (37) more suitable to the military environment (Figure 3). These have already been successfully tested in the field by the $N$ British Military in Kosovo and US scanners will shortly be deployed with Field Hospitals. The development of the technology continues to move forward with the aim to ultimately produce rugged pocket-sized ultrasound machines for use in forward surgical positions. Increased skill with the use of US in assessing wounded servicemen should lead to a reduction in the rate of negative laparotomy in future conflicts.

\section{Training and accreditation}

Training and accreditation in the use of US in trauma has been a contentious issue wherever this technology has been 
introduced into the hands of nonradiologists. In Germany ultrasound training and experience is incorporated into surgical residency training and is a requirement for board certification. In the United States of America US courses have developed under the auspices of the American College of Surgeons and the Eastern Association for the Surgery of Trauma. The amount of training and the number of patient examinations needed to achieve competence in the procedure has not been clearly established. Early recommendations varied between one hour of formal instruction (13) and 32 hours (6). Thomas (38) published a report on the accreditation of surgeon-performed FAST after only an 8-hour trauma US course. Their results were excellent ( $81 \%$ sensitivity, 99\% specificity and $98 \%$ accuracy) and an 8-hour course divided into 4 hours of theory and 4 hours of practical has been established by the American College of Surgeons. Initial studies that looked at the influence of experience with US and the ability to detect organ specific injuries suggested that experience played an important role (39). However, this has been shown to be far less significant with the FAST technique and its attention simply on detection of haemoperitoneum. The number of supervised patient examinations that are required to attain competence remains open for debate. Recommendations vary between 50 (38) and 200 (12) exams. Recent work by Shackford (40) redefined the FAST learning curve and suggested that as few as 10 scans were required, depending on the prevalence of positives whilst using cumulative sum analysis. McCarter (41) described an accuracy of $90 \%$ from the outset of training with no learning curve. Until further data is available most institutions still recommend 50 supervised scans.

The development of a US simulator machine that reproduces three-dimensional images in real time has been shown to compare favourably with patient exams as a training tool (42). Such new technology may go some way to addressing these training problems.

Based on the above data, a British Triservice trauma US course has been developed to teach non-radiologists the FAST technique. The inaugural course commenced in June 2001.

\section{Conclusion}

FAST is now accepted as the best and most cost-effective diagnostic modality for the initial examination of the injured patient throughout Europe and North America. Incorporation of FAST into surgical and accident and emergency training and the introduction of FAST into military casualty algorithms should be made a priority and will be a valuable adjunct in the rapid assessment of severely injured patients.

\section{Acknowledgement}

A grant from the Drummond Foundation allowed a detailed assessment to be undertaken of the training required for General Surgeons to use Ultrasound in the assessment of abdominal trauma.

\section{References}

1. Kristensen JK, Buemann B, Kuhl E. Ultrasonic scanning in the diagnosis of splenic haematomas. Acta Chir Scand 1971; 13: 657.

2. Asher WM, Parvin S, Virgilio RW. Echographic evaluation of splenic injury after blunt trauma. Radiology 1976; 118: 411.

3. Chambers JA, Pillbrow WJ. Ultrasound in abdominal trauma: an alternative to peritoneal lavage. Arch Emerg Med 1988; 5: 26.

4. Hoffman R, Nerlich M, Muggia-Sullam M et al. Blunt abdominal trauma in cases of multiple trauma evaluated by ultrasonography: a prospective analysis of 291 patients. F Trauma 1992; 32: 452.

5. Liu M, Lee CH, P'eng FK. Prospective comparison of diagnostic peritoneal lavage, computed tomographic scanning and ultrasonography for the diagnosis of blunt abdominal trauma. $f$ Trauma 1993; 35: 267-270.

6. Rozycki GS, Oschner MG, Jaffin JH, Champion HR. Prospective evaluation of surgeons' use of ultrasound in the evaluation of trauma patients. $\mathcal{F}$ Trauma. 1993; 34: 516-526.

7. Rozycki GS, Ochsner GM, Schmidt JA, et al. A prospective study of surgeon-performed ultrasound as the primary adjuvant modality for injured patient assessment. F Trauma 1995; 39: 492-500.

8. McKenney M, Lentz K, Nunez D, Sosa J, Sleeman D, Axelrad A, Martin L, Kirton O, Oldham C. Can ultrasound replace diagnositic peritoneal lavage in the assessment of blunt trauma. F Trauma, 1994; 37: 339-441.

9. Bain IM, Kirby RM, Tiwari P, McCaig J, Cook AL, Oakley PA, Templeton J, Braithewaite M. Survey of abdominal ultrasound and diagnositic peritoneal lavage for suspected intra-abdominal injury following blunt trauma. Injury 1998; 29(1): 65-71.

10. Boulanger BR, McLellan BA, Brenneman FD, Ochoa J, Kirkpatrick AW. Prospective evidence of superiority of a sonography based algorithm in the assessment of blunt abdominal injury. $f$ Trauma 1999; 47(4): 632-637.

11. Wherry DC, Punzalan CMK. Imaging in abdominal trauma. Trauma 2000; 2(283-90).

12. Scalea TM, Rodriguez A, Chiu WC, Brenneman FD, Fallon WF Jr, Kato K, McKenney MG, Nerlich ML, Ochsner MG Jr, Yoshii H. Focused Assessment with Sonograpy for Trauma (FAST): Results from an International Consensus Conference. 7 Trauma $1999 ; 46(3)$ : 444-472.

13. Tso P, Rodriguez A, Cooper C, et al, Sonography in blunt abdominal trauma: a preliminary progress report. F Trauma 1992; 33: 39.

14. Dolich MO, McKenney MG, Varela JE, Compton RP, McKenney KL, Cohn S. 2576 ultrasounds for blunt abdominal trauma. 7 Trauma 2001; 50: 108112.

15. Healey MA, Simons RK, Winchell RJ, Gosink BB, Casola G, Steele JT, Potenza BM, Hoyt DB. A prospective evaluation of abdominal ultrasound in blunt trauma: is it useful? F Trauma $1996 ; 40(6)$ : $875-885$.

16. McKenney MG, Martin L, Lentz K, Lopez C, Sleeman D, Aristide G, Kirton O, Nunez D, Najjar R, Namias, Sosa J. 1000 consecutive ultrasounds for blunt abdominal trauma. I Trauma, 1996. 40(4): 607-612.

17. Boulanger BR, Brenneman FD, Mclellan BA, Rizoli SB, Culhane J, Hamilton P. A prospective study of emergent abdominal sonography after blunt trauma. F Trauma 1995; 39(2): 325-330.

18. Rozycki GS, Shackford SR. Trauma Ultrasound for Surgeons, in Ultrasound for the Surgeon, S. ED, Editor 1997; Lippincott-Raven: New York. 120-135. 
19. Buzzas GR, Kern SJ, Smith SR, Harrison PB, Helmer SD, Reed JA. A comparison of sonographic examinations for trauma performed by surgeons and radiologists. F Trauma 1998; 44(4): 604-608.

20. Oschner MG. The basic abdominal ultrasound exam for the presence of fluid in the abdomen. Trauma Q, 1997; 13: 173-189.

21. Chiu WC, Cushing BM, Rodriguez A, Ho SM, Mirvis SE, Shanmuganathan K, Stein $M$. Abdominal injuires without haemoperitoneum: a potential limitation of Focused Abdominal Sonography for Trauma. $f$ Trauma 1997; 42(4): 617-625.

22. Ballard RB, Rozycki GS, Newman PG, Cubillos JE, Salomone JP, Ingram WL, Feliciano DV. An algorithm to reduce the incidence of false-negative FAST examinations in patients at high risk for occult injury. Focused Assessment for the Sonographic Examination of the Trauma patient. fournal of the American College of Surgeons 1999; 189(2): $145-150$.

23. Huang $M$, Liu $M, W u J$, Shih $H$, Ko T, Lee C. Ultrasonography for the evaluation of haemoperitoneum during resucitation: a simple scoring system. F Trauma 1994; 36: 173-177.

24. McKenney KL, McKenney MG, Nunez DB, McDowell L, Martin L. Interpreting the trauma ultrasound; observations in 62 positive cases. Emerg Radiol 1996; 3: 113-117.

25. Kahdi F, Udobi KF, Rodriguez A, Chiu WC, Scalea TM., Role of ultrasonography in penetrating abdominal trauma: a prospective clinical study. $\mathcal{f}$ Trauma 2001; 50: 475-479.

26. Fry WR, Smith RS, Organ JCH. Ultrasonic examination to wound tracts. Arch Surg 1995; 130: 605.

27. Rozycki GS, Feliciano DV, Davis TP. Ultrasound as used in thoracoabdominal trauma. Surg Clin North Am 1998; 78: 295-310.

28. Rozycki GS, Feliciano DV, Schmidt JA, Cushman JG, Sisley AC, Ingram W, Ansley JD. The role of surgeon-performed ultrasound in patients with possible cardiac wounds. Annals of Surgery 1996; 223(6): 737-746.

29. Rozycki GS, Feliciano DV, Oschner MG, Knudson MM, Hoyt DB, Davis F, Hammerman D, Figuerdo V, Harviel DJ, Han DC, Scmidt JA. The role of ultrasound in patients with possible penetrating cardiac wounds: a prospective multicenter study. $\mathscr{f}$ Trauma 1999; 46(4): 543-552.

30. Sisley AC, Rozycki GS, Ballard RB et al. Rapid detection of traumatic effusion using surgeonperformed ultrasound. F Trauma 1998; 44: 291-297.
31. Dulchavsky SA, Schwarz KL, Kirkpatrick AW, D Billica RD, Williams DR, Diebel LN, Campbell $>$ MR, Sargysan AE, Hamilton DR. Prospective Evaluation of Thoracic Ultrasound in the Detection of Pneumothorax. F Trauma 2001; 50(2): 201-205.

32. Fenkl R, von Garrel T, Knaepler H. Emergency $\unrhd$ diagnosis of strernum fracture with ultrasound $\bigcirc$ (German). Unfallchirug 1992; 95(8): 375-379.

33. Sarkisian AE, Khonkarian RA, Amirbekian NM et क़? al. Sonographic screening of mass casualities for abdominal and renal injuries following the $1988 \stackrel{0}{\Omega}$ Armenian earthquake. F Trauma 1991; 31: 247.

34. Coupland RM. Epidemiological approach to surgical management of the casualties of war. $\mathrm{Br} \overline{\bar{\omega}}$ Med f 1994; 308: 1693-1697.

35. Hardaway RM III. Vietnam wound analysis. $f \stackrel{\varnothing}{\circ}$ Trauma 1978; 18: 635-42.

36. Sustic A, Miletic D, Fuckar Z, Mraovic B, Dimec D, Mozetic V. Ultrasonography in the evaluation of haemoperitoneum in war casualities. Military $\overrightarrow{\vec{\omega}}$ Medicine 1999; 164(8): 600-602.

37. Wherry DC. Potential of a hand-held ultrasound in assessment of the injured patient. Cardiovascular Surgery $1998 ; \mathbf{6 ( 6 )}: 569-572$

38. Thomas BT, Falcone RE, Vasquez D et al. $\vec{A}$ Ultrasound evaluation of blunt abdominal trauma: program implementation, initial experience, and learning curve. $\mathcal{F}$ Trauma 1997; 42: 384-390.

39. Forster R, Pillasch J, Zielke A, Malewski U, Rothmund $M$. Ultasonography in blunt abdominal trauma: influence of the investigator's experience. $\mathcal{F}$ Trauma 1992; 34(2): 264-269.

40. Shackford SR, Frederick RB, Osler TM, Trabulsy ME, Clauss DW, Vane DW. Focused Abdominal Sonogram for Trauma: the learning curve of non radiologist clinicians in detecting haemoperitoneum. F Trauma 1999; 46(4): 553-564. 41. McCarter FD, Luchette FA, Molloy M, Hurst JM, Davis K Jr, Johannigman JA, Frame SB, Fischer JE Institutional and individual learning curves for focused abdominal ultrasound for trauma: cumulative sum analysis. Annals of Surgery 2000; 231(5): $689-700$.

42. Knudson MM, Sisley AC. Training residents using simulation technology: experience with ultrasound for trauma. F Trauma 2000; 48(4): 659-665.

43. Nagy KK, Roberts RR, Joseph KT et al. Experience with over 2500 diagnostic peritoneal lavages. Injury 2000; 31(7): 479-482.

44. Catre MG. Diagnositic peritoneal lavage versus abdominal computed tomography in blunt abdominal trauma: a review of prospective studies. Can f surg 1995; 38(2): 117-122. 